\title{
A Systematic Review of Teaching Daily Living Skills to Adolescents and Adults with Autism Spectrum Disorder
}

\author{
Kyle D. Bennett • Charles Dukes
}

Received: 3 July 2013 / Accepted: 13 July 2013 / Published online: 24 October 2013

(C) Springer Science+Business Media New York 2013

\begin{abstract}
We examined the peer-reviewed literature on teaching daily living skills to secondary students (ages 12-22 years) with Autism Spectrum Disorder (ASD) and Intellectual Disabilities (ID). A systematic search of the literature spanning January 2000-October 2012 was conducted, and 14 studies meeting the inclusion criteria were identified. Overall, there is limited research examining instructional tactics for teaching daily living skills to this population. Features of the studies are presented, and a classification of the studies' results (i.e., positive, negative, mixed) and certainty of evidence (i.e., suggestive, preponderance, conclusive) are discussed.
\end{abstract}

Keywords Autism Spectrum Disorder · Adolescents · Daily living skills · Functional skills · Instruction

For decades, professionals have recognized the importance of teaching functional skills to individuals with disabilities (e.g., Ayers et al. 2011; Brown et al., 1979; Siegel 1996). Daily living skills are among the functional skills needed for success in current and future environments, and they consist of those activities needed in domestic, employment, and community settings that allow a person to be as independent as possible (Brown et al. 1979; Test et al. 2006; Volkmar and Wiesner 2009).

Individuals with Autism Spectrum Disorder (ASD) should acquire a variety of daily living skills if they are to be successful in post-school environments (Carothers and Taylor

K. D. Bennett $(\square)$

College of Education, Florida International University,

11200 S.W. 8th Street, Miami, FL 33199, USA

e-mail: kyle.bennett@fiu.edu

C. Dukes

Florida Atlantic University, Boca Raton, FL, USA
2004). Ideally, such skills are taught during an individual's formative years in school starting well before graduation, irrespective of a student's post-graduation plans (Ayers et al. 2011; Smith and Targett 2009). Unfortunately, many adolescents and adults with ASD experience challenges acquiring the skills needed for independent functioning, including those needed for home life, employment, and participation in community events (Hendricks and Wehman 2009). Consequently, integration into post-school settings can be hindered resulting in dependence on others (Hendricks and Wehman 2009; Targett and Smith 2009).

Recognizing the importance of teaching daily living skills to students with ASD, several researchers have conducted reviews of the literature on this topic. These reviews included studies that: (a) investigated specific categories of daily living skills (e.g., social skills), (b) evaluated specific treatments to develop these skills (e.g., applied behavior analysis), or (c) examined the development of daily living skills among specific populations (e.g., individuals with ASD with an IQ above 70). For instance, Flynn and Healy (2012) examined the literature on improving social skills and self-help skills among this population. Twenty-two studies were identified with the majority being related to social skills development $(n=16)$, and many of these studies had younger children as participants. A variety of interventions was discussed showing varying degrees of effectiveness. Matson, Hattier, and Belva (2012) provided an examination of the literature on teaching adaptive living skills among individuals with ASD using Applied Behavior Analysis (ABA) tactics as the teaching approach and concluded that it was effective for teaching these skills to this population. Although the Matson et al. (2012) review summarized the literature well, it was not a systematic review, and thus, it is possible that other studies might have been included (Palmen et al. 2012). In another review, Palmen et al. (2012) examined the literature on the use of behavioral interventions to teach adaptive skills to young 
adults with ASD considered high functioning. To be included in this review, studies had to have at least one participant with ASD 16 years or older with a full scale IQ, or verbal IQ, of 70 or above, or be described as high functioning. An additional feature of the Palmen et al. review included the categorization of the study results (i.e., positive, negative, or mixed) and the certainty of evidence (i.e., suggestive, preponderance, or conclusive) based on a heuristic evaluating the design features of each study. This provided a detailed analysis, beyond a qualitative review, allowing greater insight into the design features of the reviewed studies, revealing many with positive results, but with varying degrees of certainty of evidence.

The reviews outlined provide important summaries of the literature. Such work guides future research as well as practice in home, school, and community settings. Nevertheless, there appears to be a gap related to examining the literature on instructional strategies to teach daily living skills to secondary students (ages 12-22 years) with ASD with reported IQ scores in the intellectual disabilities range. This group of individuals with ASD represents an important constituency, and an understanding of developing daily living skills among this population can guide the work of researchers, practitioners, and caregivers. Furthermore, federal education law requires evidenced-based practices be implemented, as well as emphasizes the results of special education service in postschool settings (Ayers et al., 2011). Thus, the purpose of this study was to extend that of Matson et al. (2012) and Palmen et al. (2012) by systematically reviewing research that examined daily living skills instruction among secondary students (ages 12-22 years) with ASD, including those with and without intellectual disabilities.

\section{Method}

\section{Definitions}

We examined the peer-reviewed literature on teaching daily living skills to adolescents with ASD spanning the years January 2000-October 2012. For this review, autism spectrum disorder included autistic disorder, Asperger Syndrome, and pervasive developmental disorder-not otherwise specified. Participants of the studies meeting the inclusion criteria could have had comorbid diagnoses, as well. Daily living skills included those described by the Life Centered Career Education-Modified Curriculum (LCCE-M; Loyd and Brolin 1997) including: (a) managing money, (b) selecting and maintaining living environments, (c) caring for personal health, (d) developing and maintaining appropriate intimate relationships, (e) eating at home and in the community, (f) cleaning and purchasing clothing, (g) participating in leisure/ recreational activities, and $(\mathrm{h})$ getting around in the community.
We chose to guide our review by using the Daily Living Skills Curriculum Area of the LCCE-M Curriculum as it provided a finite scope of daily living skills with each competency broad enough to encompass a variety of behaviors.

\section{Search Procedures}

We completed a systematic review of the literature by conducting journal hand searches, electronic database searches, and a bibliographic search (Wolery and Lane 2010). Hand searches were conducted in the following journals: Focus on Autism and Other Developmental Disabilities, Education and Training in Autism and Developmental Disabilities, Journal of Applied Behavior Analysis, and Research in Autism Spectrum Disorders. Additionally, electronic database searches were completed using the following databases: Education Resources Information Center (ERIC), Education Full Text, Psych Info, and PsychArticles. Keywords used for the database searches included the population terms: (a) autism spectrum disorder, (b) autism, (c) Asperger syndrome, and (d) pervasive developmental disorder-not otherwise. Each of these terms was paired with the keywords: (a) daily living skills, (b) self-care skills, (c) self-help skills, (d) life skills, (e) functional skills, (f) leisure skills, and (g) recreation skills. Following the hand and database searches, we conducted a bibliographic search of the studies meeting the inclusion criteria.

\section{Inclusion Criteria}

Articles had to meet several criteria to be included in this review. First, studies had to be published in the peerreviewed literature between January 2000 and October 2012. Next, at least half of the participants in a study had to have a diagnosis as previously described. We selected this criterion to ensure at least a balanced representation of participants with ASD. Further, limits were not placed on participants' IQ scores to extend the research of Palmen et al. (2012). At least half of the participants in a study had to be between the ages 12-22 years. We selected this criterion to allow for an equal representation of students at the secondary level of instruction. Additionally, the studies had to use a single-subject research design. This criterion was chosen to focus our examination of the contributions of the single-subject research literature pertaining to daily living skill instruction. The independent variable had to be an intervention or intervention package, while the dependent variable(s) had to meet the definition of a daily living skill as previously described. Finally, studies aimed at examining vocational and employment skill development were not included in this review, as recent researchers have presented that information (see Bennett and Dukes 2013; Hendricks and Wehman 2009). 


\section{Reliability of Inclusion Criteria}

The first and second authors screened studies from the hand, database, and bibliographic searches for potential inclusion in this review. From this initial screening, we identified 17 studies for further examination using the inclusion criteria. Of these 17 studies, there was $100 \%$ agreement to include 14 and exclude three. We excluded a study by Myles, Ferguson, and Hagiwara (2007) due to its focus on homework assignments. We also excluded a study by Chezan, Drasgow, and Marshall (2012) because the dependent variable was collateral academic skills. Neither of these studies met the definition of daily living skills we employed from the LCCE-M Curriculum. Finally, we excluded a study by Copeland and Hughes (2000). Although the skills under investigation in that study were daily living skills, the purpose was to develop employment skills needed in faculty dining rooms and hotels.

\section{Data Extraction and Coding}

Data were extracted and coded using similar procedures as Palmen et al. (2012). The first and second authors independently summarized the studies to include information regarding (a) participants' diagnoses, (b) participants' ages, (c) targeted skills, (d) the intervention, (e) the setting, and (f) the LCCE-M competency matching the targeted skills.

After summarizing the studies, the authors independently classified the results as positive, negative, or mixed. A rating of positive results was given if all the participants and/or all skills improved as compared to baseline measures. A rating of negative results was given if all the participants and/or skills remained unchanged from baseline or declined. A rating of mixed results was given if some of the participants and/or targeted skills improved, while others either remained unchanged or declined relative to baseline (Machalicek et al., 2008; Palmen et al., 2012).

Following the classification of the results of the studies, the authors independently used a modified heuristic evaluating the certainty of evidence (i.e., suggestive, preponderance, or conclusive evidence) based on each study's design features (Lang et al. 2010; Palmen et al., 2012; Ramdoss et al., 2011). Studies were classified as conclusive evidence if they met the following criteria including, (a) an experimental design, (b) interobserver agreement (IOA) collected at least $20 \%$ of the sessions with agreement coefficients at $80 \%$ or better, (c) clearly defined dependent variables, (d) detailed descriptions of the independent variable sufficient for replication, and (e) design features that provided at least some controls for alternative explanations of the results. Studies were classified as preponderance of evidence if they met criteria (a) through (d) presented above, but had limitations in their control for potential alternative explanations for the results. Studies were classified as suggestive of evidence if a pre-experimental design (A-B design) was used, or if any one of the criteria (a) through (d) were not met. A plus $(+)$ was recorded if a design feature was present and a minus (-) if it was not present.

Other investigators (Palmen et al., 2012; Ramdoss et al., 2011) included treatment fidelity (procedural reliability) as part of their decision model when categorizing a study using the certainty of evidence heuristic. However, Palmen et al. (2012) indicated that few studies in their review included treatment fidelity procedures, and they relied upon other characteristics of a study to evaluate the potential for treatment fidelity (e.g., video recorded sessions, the use of a flowchart, the use of self-management tools). Ramdoss et al. (2011) relied on other features of studies to evaluate the potential for treatment fidelity as well (e.g., replication of an experiment, presence of researchers). This has the potential to incorrectly classify a study's certainty of evidence according to this heuristic, which includes treatment fidelity used as a feature against which a study is evaluated. Potentially, this limits the utility of the heuristic, but more extensive use will better address such issues. Although the topic of treatment fidelity was discussed at least three decades ago by Billingsley, White, and Munson (1980), it appears that the wide scale acceptance of this measure has only emerged in recent years, potentially leaving older studies vulnerable to misclassification using this heuristic. Therefore, we decided to report whether a study detailed treatment fidelity procedures and the results of such measures, but not to include the measure as part of the decision when categorizing a study based on its certainty of evidence. A plus $(+)$ was recorded if treatment fidelity data were collected at least $20 \%$ of the sessions with a treatment fidelity coefficient of at least $80 \%$. A minus (-) was recorded if treatment fidelity data were collected less than $20 \%$ of the sessions or if the treatment fidelity coefficient was below $80 \%$. A "not reported" (NR) was recorded if information pertaining to treatment fidelity was absent.

\section{Reliability of Data Extraction and Coding}

The first and second authors independently coded the items presented in Tables 1 and 2. Items used to evaluate IOA included: (a) number of participants with ASD; (b) age range of participants with ASD; (c) target behavior; (d) intervention; (e) setting(s); (f) LCCE-M competency; (g) results of the study; (h) experimental design; (i) IOA, (j) TF; (k) operational definition(s) of the dependent variable(s); (l) independent variable detailed for replication; and $(\mathrm{m})$ control for alternative explanations of the results. A total of 182 items were scored across the 14 studies. The only item not used in evaluating IOA was the level of certainty since it was an overall score 


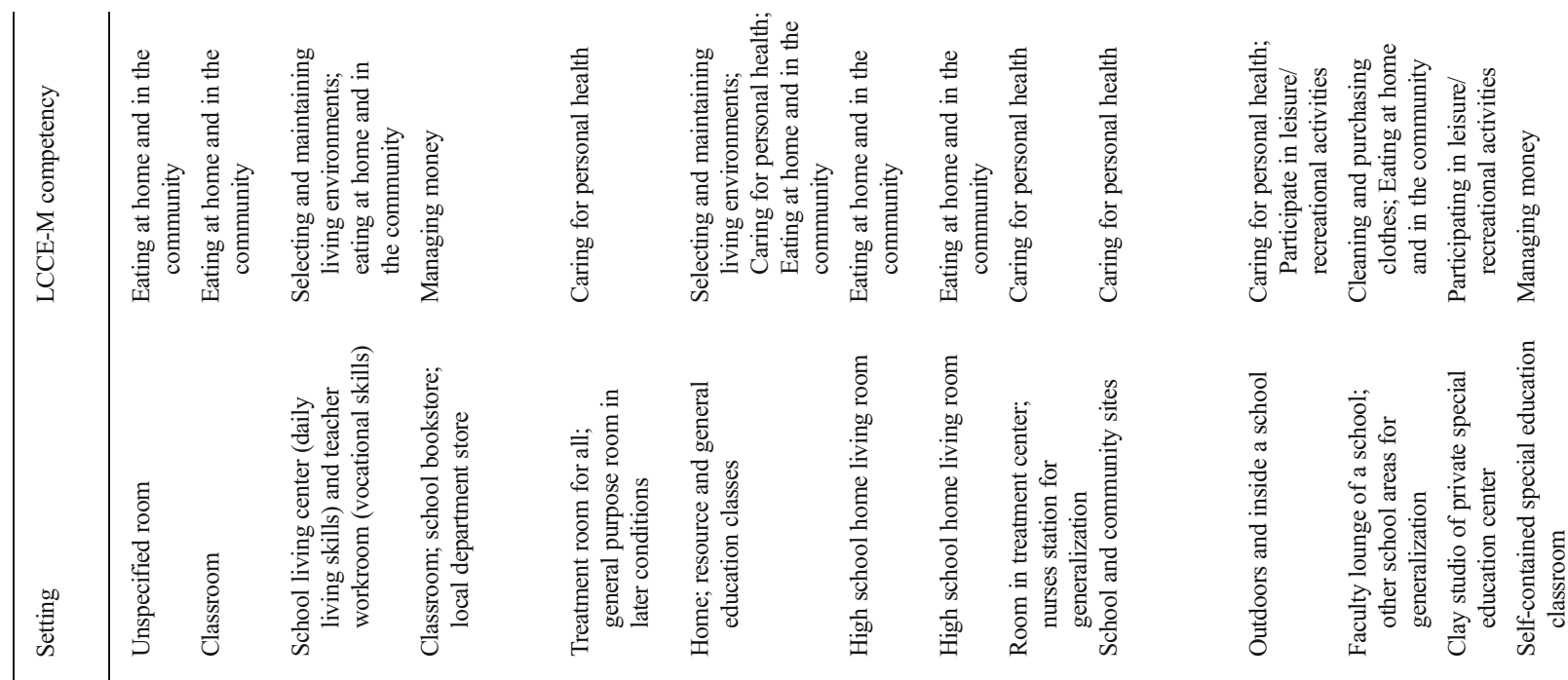

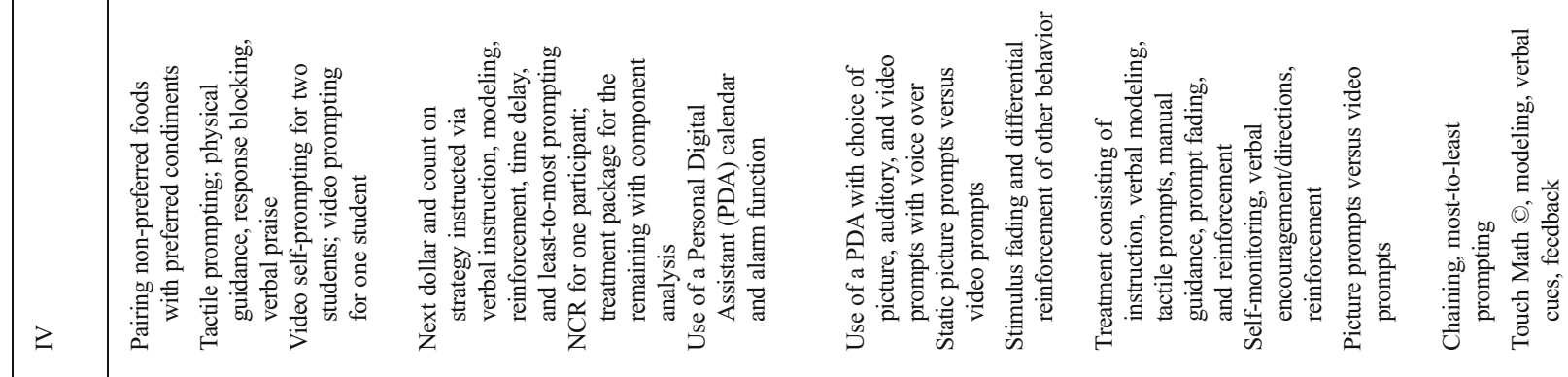

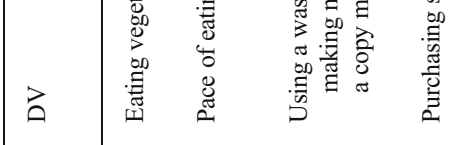

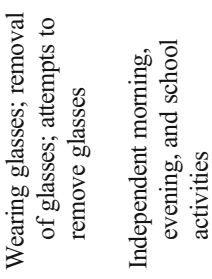

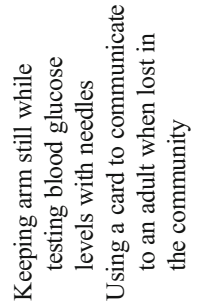

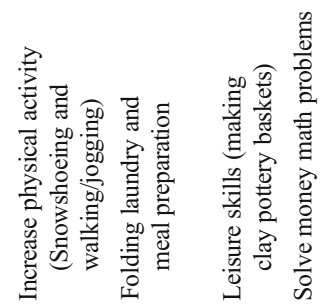

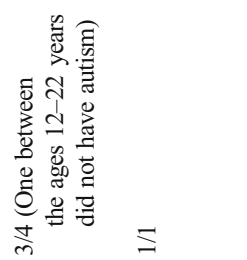

量
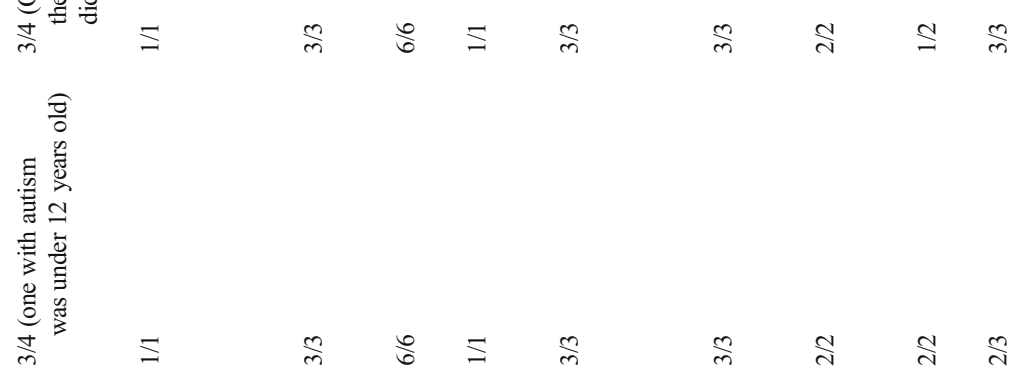

$\equiv m$

$=\frac{m}{m} \stackrel{m}{m}$

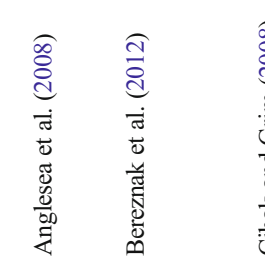

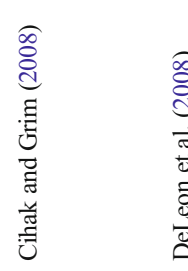

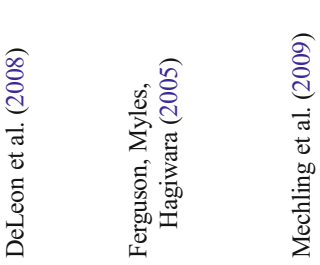

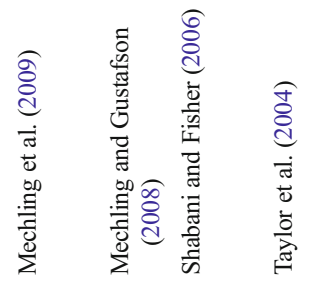

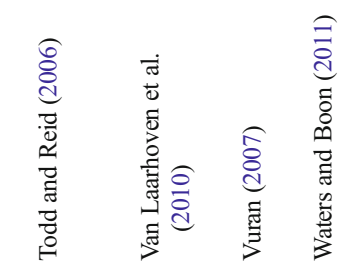


Table 2 Results of studies and certainty of evidence

\begin{tabular}{|c|c|c|c|c|c|c|c|c|}
\hline Study & Results & Design & IOA & $\mathrm{TF}$ & $\begin{array}{l}\text { Operationally } \\
\text { defined dependent } \\
\text { variable }\end{array}$ & $\begin{array}{l}\text { Detailed } \\
\text { intervention } \\
\text { for replication }\end{array}$ & $\begin{array}{l}\text { Control for } \\
\text { alternative } \\
\text { explanations }\end{array}$ & $\begin{array}{l}\text { Level of } \\
\text { certainty }\end{array}$ \\
\hline Ahearn (2003) & Positive & $\begin{array}{l}\text { Multiple baseline design } \\
\text { with reversals }\end{array}$ & + & NR & + & + & + & Conclusive \\
\hline Anglesea et al. (2008) & Positive & Reversal & - & NR & + & + & - & Suggestive \\
\hline Bereznak et al. (2012) & Positive & $\begin{array}{l}\text { Multiple probe design } \\
\text { across behaviors and } \\
\text { replicated across } \\
\text { participants }\end{array}$ & + & + & + & + & + & Conclusive \\
\hline Cihak and Grim (2008) & Positive & $\begin{array}{l}\text { Multiple probe design } \\
\text { across behaviors and } \\
\text { settings }\end{array}$ & + & + & + & + & + & Conclusive \\
\hline DeLeon et al. (2008) & Positive & $\begin{array}{l}\text { Reversal design with an } \\
\text { added component } \\
\text { analysis }\end{array}$ & + & NR & + & + & + & Conclusive \\
\hline Ferguson et al. (2005) & Mixed & $\begin{array}{l}\text { Multiple baseline design } \\
\text { across settings }\end{array}$ & + & NR & + & - & - & Suggestive \\
\hline Mechling et al. (2009) & Positive & $\begin{array}{l}\text { Multiple probe design } \\
\text { across behaviors and } \\
\text { replicated across } \\
\text { participants }\end{array}$ & + & + & + & + & + & Conclusive \\
\hline $\begin{array}{l}\text { Mechling and } \\
\text { Gustafson (2008) }\end{array}$ & Positive & $\begin{array}{l}\text { Adapted Alternating } \\
\text { Treatments Design }\end{array}$ & + & + & + & + & + & Conclusive \\
\hline Shabani and Fisher (2006) & Positive & Reversal Design & + & NR & + & + & + & Conclusive \\
\hline Taylor et al. (2004) & Positive & $\begin{array}{l}\text { Multiple baseline design } \\
\text { across participants }\end{array}$ & + & NR & + & + & - & Preponderance \\
\hline Todd and Reid (2006) & Positive & $\begin{array}{l}\text { Changing conditions } \\
\text { design }\end{array}$ & - & - & + & + & - & Suggestive \\
\hline Van Laarhoven et al. (2010) & Positive & $\begin{array}{l}\text { Adapted Alternating } \\
\text { Treatments Design }\end{array}$ & + & + & + & + & - & Preponderance \\
\hline Vuran (2007) & Positive & $\begin{array}{l}\text { Multiple probe design } \\
\text { across participants }\end{array}$ & + & + & + & + & - & Preponderance \\
\hline Waters and Boon (2011) & Positive & $\begin{array}{l}\text { Multiple probe design } \\
\text { across participants }\end{array}$ & + & + & + & + & + & Conclusive \\
\hline
\end{tabular}

based on the previous ratings and duplicative. A plus (+) was scored for agreements and a minus $(-)$ was scored for disagreements. Initial IOA was calculated by dividing the number of agreements by the number of agreements plus disagreements, and multiplying by 100 . The initial IOA was $90.7 \%$. In the case of disagreements, the authors discussed the discrepancies and came to consensus to accurately present the studies meeting the inclusion criteria.

\section{Results}

We identified 14 studies meeting the inclusion criteria. With the exception of 2008, there were 0-2 studies identified per year throughout this timeframe. Further, there was only one publication meeting the inclusion criteria each of the last 4 years with no trend in publication frequency (see Fig. 1).

\section{Characteristics of the Included Studies}

The total participants in the reviewed studies was $n=39$. Thirty-seven participants were identified as having ASD as

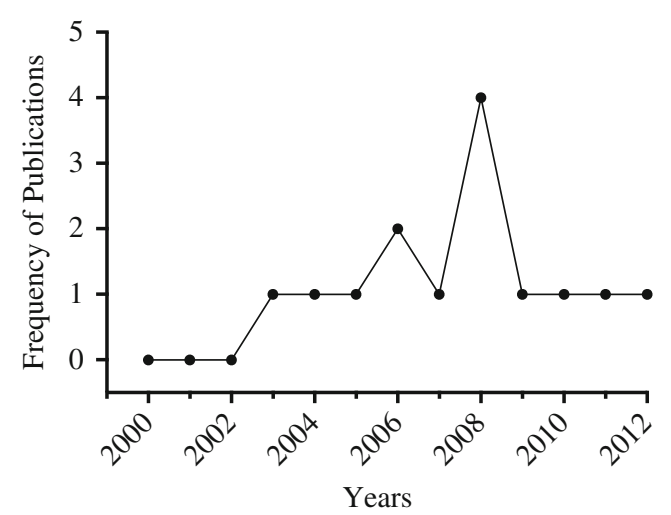

Fig. 1 Frequency of publications meeting inclusion criteria January 2000-October 2012 
well as between the ages 12-22. Additionally, the majority of the participants in 13 of the studies were either identified as having an IQ score below 70, were identified as having an intellectual disability without specifying the IQ score, or they were described as attending separate day schools. A variety of dependent variables were examined including behaviors related to eating, domestic skills, purchasing and solving money related math problems, safety and health skills, independent routines, leisure skills, and cooking. Furthermore, the teaching strategies used in each study were based on ABA, including chaining, prompting and fading, video-based instruction, pairing, self-monitoring, and differential reinforcement, to name a few. The research studies were conducted in several different types of settings, including therapy rooms, classrooms, school facilities (e.g., bookstore), homes, outdoors, and community sites (see Table 1 for details from each study).

\section{Evaluation of the Results}

We evaluated the results of each of the reviewed studies using procedures similar to Machalicek et al., 2008 and Palmen et al., 2012. The results from 13 studies demonstrated positive results. Only one study, Ferguson, Myles, and Hagiwara (2005), demonstrated mixed results, and none of the reviewed studies showed negative results (see Table 2).

\section{Evaluation of the Certainty of Evidence}

We also evaluated the certainty of evidence of each study using a modified heuristic (see Table 2). Eight studies were identified as having conclusive evidence. Three studies were classified as demonstrating a preponderance of evidence. The study by Taylor, Hughes, Richard, Hoch, and RodriguezCoello (2004) included different teaching procedures that were used during the school and community sessions. Although the results of the interventions were positive, the differences in the teaching strategies precluded this study from meeting the criteria for conclusive evidence since the relative contribution of each set of teaching procedures is unknown. We also classified the study by Van Laarhoven, Kraus, Karpman, Nizzi, and Valentino (2010) as meeting the criteria for preponderance of evidence. There were minimal baseline data, as well as no discernable control condition to examine the influence of maturation or multiple treatment interference. Finally, the study by Vuran (2007) was classified as meeting a preponderance of evidence as only two tiers of a multiple baseline design were examined, rather than at least three tiers (Kratochwill et al., 2010). Finally, we classified the certainty of evidence of three studies as suggestive. Angelesea, Hoch, and Taylor (2008) reported that IOA data were collected below the $20 \%$ criteria. The study by Ferguson, Myles, and Hagiwara (2005) was also classified as suggestive. Although IOA data were collected at school, it was unclear if it was collected at home. Furthermore, we did not rate the description of the independent variable as being detailed enough to permit replication, particularly the prompts needed for corrections. Moreover, there were ascending trends evident in two out of the three baselines, which may indicate difficulty with experimental control. The last study classified as suggestive of evidence was by Todd and Reid (2006). It was unclear if Todd and Reid collected IOA data on the dependent variable. Additionally, they used a changing conditions design, and this design limits the ability to determine a functional relationship (Richards et al. 2014).

\section{Discussion}

The purpose of this review was to examine the research on teaching daily living skills to secondary students with ASD and ID. Through a systematic search of the literature, we identified and reviewed 14 intervention studies on the development of a variety of daily living skills. We classified most of the results as positive, but with varying degrees of certainty of evidence.

This paper contributes to the literature in several ways. First, there was very little overlap between the findings presented in this review and the three recent reviews previously identified. Specifically, there was one study that overlapped with Flynn and Healy (2012), three that overlapped with Matson et al. (2012), and one that overlapped with Palmen et al. (2012). Thus, additional studies were identified in the current review that might guide researchers with future studies, as well as practitioners designing and implementing instructional procedures with this population. Second, 13 of the identified studies were comprised of participants described as experiencing an intellectual disability, or were identified as students in center-based school programs. This extends the findings of Palmen et al. (2012) who identified 20 studies on daily living skills development among young adults considered high functioning. Third, although we identified additional research on developing daily living skills among individuals with ASD, we concur with Matson et al. (2012) and Palmen et al. (2012) in that overall, there is a scarcity of research on this topic. This shortage of research seems even more pronounced considering individuals with ASD functioning in the range of intellectual disabilities. Indeed, the frequency of publications spanning the last 12 years has been exceedingly low with no trend. Furthermore, given that single-subject research design requires multiple replications to increase the external validity of an intervention (Horner et al., 2005), this issue is compounded since none of the studies examined the same dependent variables using similar 
procedures. Perhaps through additional research, including replication studies, future researchers will identify efficient teaching procedures to assist adolescents and adults with ASD achieving independence in post-school environments (Bennett and Dukes 2013), an issue known to be problematic and with deleterious effects for the individual, their family, and society (Cimera and Cowan 2009; Hendricks and Wehman, 2009; Lawer et al. 2009; Targett and Smith 2009). Moreover, additional studies can assist educators in meeting the requirements set forth by federal education legislation that requires evidence-based practices that lead to positive results in post-school settings.

Similar to Palmen et al. (2012), and others who have conducted systematic reviews of the literature (e.g., Ramdoss et al., 2011), we evaluated the certainty of evidence of studies using a heuristic. Among the criteria evaluated in determining a study's certainty of evidence was treatment fidelity. Collecting and reporting on the consistency with which an independent variable is delivered as intended increases both the internal and external validity of a study (Billingsley et al., 1980). Although the importance of procedural fidelity has been discussed for some time, and it is an important feature of intervention studies (Gast, 2010), we speculate that its wide-scale use may have only recently emerged given the criteria of what constitutes evidencebased instruction via entities such as the What Works Clearinghouse. For instance, some studies reviewed by Palmen et al. (2012) and Ramdoss et al. (2011) did not report treatment fidelity data, and this was found in the current review even among recent publications. If the heuristic were followed as designed, these studies would have been classified as "suggestive" of evidence. However, Palmen et al. and Ramdoss et al. used other features of the studies' designs that might have indicated treatment fidelity, and thus, rated the studies as having a higher certainty of evidence (i.e., preponderance or conclusive). This practice has the potential of misclassifying some studies, as well as limits the consistency with which studies are evaluated using the heuristic. As an alternative, we listed whether a study reported treatment fidelity as well as evaluated the quality of the measure reported (e.g., data collected at least $20 \%$ of the sessions with coefficients of $80 \%$ or better). However, we did not use the presence or absence of treatment fidelity in categorizing studies as suggestive, preponderance, or conclusive, recognizing that some studies, including recent studies, might have demonstrated clear experimental control but did not collect and report treatment fidelity data (e.g., Ahearn 2003; DeLeon et al. 2008). This provides a reader with information on the presence or absence of treatment fidelity without potentially misclassifying studies in either direction (i.e., giving a higher or lower certainty of evidence rating).

An additional issue discovered using this heuristic was the IOA on the item, "some controls for alternative explanations."
Although our overall initial IOA was $90.7 \%$, on that specific item, it was $57.1 \%$ before correction and consensus between the authors. The notion of "some controls" introduced a degree of subjectivity, and this item was among the more subjective in the heuristic, which may have contributed to the low IOA observed for this category. Future investigators may consider modifying this criterion to be more objective (e.g., number of potential limitations or number of potential confounds). Adding these measures may assist researchers in rating this item, although eliminating judgment, and thus subjectivity, may be difficult.

The results of this study should be considered in the presence of several limitations. The timeframe of the review, the keywords used, the journals selected for hand searches, and the databases used to identify articles meeting the inclusion criteria represent limitations of this study. Other studies not meeting our inclusion criteria might exist that could have contributed to this investigation. Additionally, limiting studies that used single-subject research methodology could have also restricted the scope of this review. Anecdotally, however, very few studies using group design were identified. Using the LCCE-M Curriculum as a guide might have reduced the amount of articles we identified as well. However, we only excluded three studies from the review using the LCCE-M Curriculum as a guide. Finally, the low IOA found on the item that rated the degree of control of the studies reviewed is another limitation of this study.

Considering the results of this review, as well as those conducted by other investigators (Matson et al., 2012; Palmen et al., 2012), additional research is clearly needed investigating the strategies to develop and maintain daily living skills among adolescents and adults with ASD. This population has the potential to live, work, and recreate in integrated community settings (Wehman et al. 2009). Many individuals with ASD can likely achieve greater independence provided families, teachers, and related service professionals have a variety of evidence-based procedures to use.

\section{References}

*Indicates study included in the review

*Ahearn, W. H. (2003). Using simultaneous presentation to increase vegetable consumption in a mildly selective child with autism. Journal of Applied Behavior Analysis, 36(3), 361-365.

*Anglesea, M. M., Hoch, H., \& Taylor, B. A. (2008). Reducing rapid eating in teenagers with autism: Use of a pager prompt. Journal of Applied Behavior Analysis, 41(1), 107-111. doi:10.1901/jaba.2008. 41-107.

Ayers, K. M., Lowery, K. A., Douglas, K. H., \& Sievers, C. (2011). I can identify Saturn but I can't brush my teeth: What happens when the 
curricular focus for students with severe disabilities shifts. Education and Training in Autism and Developmental Disabilities, 46(1), 11-21.

Bennett, K. D., \& Dukes, C. (2013). Employment instruction for secondary students with autism spectrum disorder: A systematic review of the literature. Education and Training in Autism and Developmental Disabilities, 48(1), 67-75.

*Bereznak, S., Ayers, K. M., Mechling, L. C., \& Alexander, J. L. (2012). Video self-prompting and mobile technology to increase daily living and vocational independence for students with autism spectrum disorders. Journal of Developmental and Physical Disabilities, 24, 269-285. doi:10.1007/s10882-012-9270-8.

Billingsley, F., White, O. R., \& Munson, R. (1980). Procedural reliability: A rationale and an example. Behavioral Assessment, 2, 229-241.

Brown, L., Branston, M. B., Hamre-Nietupski, S., Pumpian, I., Certo, N., \& Gruenewald, L. (1979). A strategy for developing chronologicalage-appropriate and functional curricular content for severely handicapped adolescents and young adults. Journal of Special Education, 13, 81-90.

Carothers, D. E., \& Taylor, R. L. (2004). How teachers and parents can work together to teach daily living skills to children with autism. Focus on Autism and Other Developmental Disabilities, 19(2), 102-104. doi:10.1177/10883576040190020501.

Chezan, L. C., Drasgow, E., \& Marshall, K. J. (2012). A report on using general-case programming to teach collateral academic skills to a student in a postsecondary setting. Focus on Autism and Other Developmental Disabilities, 27(1), 22-30. doi:10.1177/ 1088357611428334.

*Cihak, D. F., \& Grim, J. (2008). Teaching students with autism spectrum disorder and moderate intellectual disabilities to use count-on strategies to enhance independent purchasing skills. Research in Autism Spectrum Disorders, 2, 716-727. doi:10.1016/j.rasd.2008.02.006.

Cimera, R. E., \& Cowan, R. J. (2009). The cost of services and employment outcomes achieved by adults with autism in the U.S. Autism, 13(3), 285-302. doi:10.1177/1362361309103791.

Copeland, S. R., \& Hughes, C. (2000). Acquisition of a picture prompt strategy to increase independent performance. Education and Training in Mental Retardation and Developmental Disabilities, 35, 294-305.

*DeLeon, I. G., Hagopian, L. P., Rodriguez-Catter, V., Bowman, L. G., Long, E. S., \& Boelter, E. W. (2008). Increasing wearing of prescription glasses in individuals with mental retardation. Journal of Applied Behavior Analysis, 41(1), 137-142. doi:10.1901/jaba. 2008.41-137.

*Ferguson, H., Myles, B. S., \& Hagiwara, T. (2005). Using a personal digital assistant to enhance the independence of an adolescent with Asperger syndrome. Education and Training in Developmental Disabilities, 40(1), 60-67.

Flynn, L., \& Healy, O. (2012). A review of treatments for deficits in social skills and self-help skills in autism spectrum disorder. Research in Autism Spectrum Disorders, 6, 431-441. doi:10.1016/j.rasd.2011. 06.016.

Gast, D. L. (2010). General factors in measurement and evaluation. In D. L. Gast (Ed.), Single subject research methodology in behavioral sciences (pp. 91-109). New York: Routledge.

Hendricks, D. R., \& Wehman, P. (2009). Transition from school to adulthood for youth with autism spectrum disorders: Review and recommendations. Focus on Autism and Other Developmental Disabilities, 24(2), 77-88. doi:10.1177/1088357608329827.

Horner, R. H., Carr, E. G., Halle, J., McGee, G., Odom, S., \& Wolery, M. (2005). The use of single-subject research design to identify evidence-based practice in special education. Exceptional Children, $71(165), 179$

Kratochwill, T. R., Hitchcock, J., Horner, R. H., Levin, J. R., Odom, S. L., Rindskopf, D. M \& Shadish, W. R. (2010). Single-case designs technical documentation. Retrieved from What Works Clearinghouse website: http://ies.ed.gov/ncee/wwc/pdf/wwc_scd.pdf.
Lang, R., Regester, A., Lauderdale, S., Ashbaugh, K., \& Haring, A. (2010). Treatment of anxiety in autism spectrum disorders using cognitive behaviour therapy: A systematic review. Developmental Neurorehabilitation, 13(1), 53-63. doi:10.3109/17518420903236288.

Lawer, L., Brusilovskiy, E., Salzer, M. S., \& Mandell, D. S. (2009). The use of vocational rehabilitative services among adults with autism. Journal of Autism and Developmental Disorders, 39, 487-494. doi: 10.1007/s10803-008-0649-4.

Loyd, R. J., \& Brolin, D. E. (1997). Life centered career education modified curriculum for individuals with moderate disabilities. Arlington: The Council for Exceptional Children.

Machalicek, W., O'Reilly, M. F., Beretvas, N., Sigafoos, J., Lancioni, G., Sorrells, A., \& Rispoli, M. (2008). A review of school-based instructional interventions for students with autism spectrum disorder. Research in Autism Spectrum Disorders, 2, 395416. doi:10.1016/j.rasd.2007.07.001.

Matson, J. L., Hattier, M. A., \& Belva, B. (2012). Treating adaptive living skills in persons with autism using applied behavior analysis: A review. Research in Autism Spectrum Disorders, 6, 271-276. doi: 10.1016/j.rasd.2011.05.008.

*Mechling, L. C., Gast, D. L., \& Seid, N. H. (2009). Using a personal digital assistant to increase independent task completion by students with autism spectrum disorder. Journal of Autism and Developmental Disorders, 39, 1420-1434. doi:10.1007/s10803009-0761-0.

*Mechling, L. C., \& Gustafson, M. R. (2008). Comparison of static picture and video prompting on the performance of cookingrelated tasks by students with autism. Journal of Special Education Technology, 23(3), 31-45.

Myles, B. S., Ferguson, H., \& Hagiwara, T. (2007). Using a personal digital assistant to improve the recording of homework assignments by an adolescent with Asperger syndrome. Focus on Autism and Other Developmental Disabilities, 22(2), 96-99. doi:10.1177/ 10883576070220021001

Palmen, A., Didden, R., \& Lang, R. (2012). A systematic review of behavioral intervention research on adaptive skill building in highfunctioning young adults with autism spectrum disorder. Research in Autism Spectrum Disorders, 6, 602-617. doi:10.1016/j.rasd. 2011.10.001.

Ramdoss, S., Lang, R., Mulloy, A., Franco, J., O'Reilly, M., Didden, R., \& Lancioni, G. (2011). Use of computer-based interventions to teach communications skills to children with autism spectrum disorders: A systematic review. Journal of Behavioral Education, 20, 55-76. doi:10.1007/s10864-010-9112-7.

Richards, S. B., Taylor, R. L., \& Ramasamy, R. (2014). Single subject research: Applications in Educational and Clinical Settings. Belmont: Wadsworh, Cengage Learning.

*Shabani, D. B., \& Fisher, W. W. (2006). Stimulus fading and differential reinforcement for the treatment of needle phobia in a youth with autism. Journal of Applied Behavior Analysis, 39(4), 449-452. doi: 10.1901/jaba.2006.30-05.

Siegel, B. (1996). The world of the autistic child. New York: Oxford University Press.

Smith, M. D., \& Targett, P. S. (2009). Critical life skills. In P. Wehman, M. D. Smith, \& C. Schall (Eds.), Autism and the transition to adulthood: Success beyond the classroom (pp. 209-231). Baltimore: Paul H. Brookes Publishing Co.

Targett, P. S., \& Smith, M. D. (2009). Living in the community. In P. Wehman, M. D. Smith, \& C. Schall (Eds.), Autism \& the transition to adulthood: Success beyond the classroom (pp. 233-250). Baltimore: Paul H. Brookes Publishing Co.

*Taylor, B. A., Hughes, C. E., Richard, E., Hoch, H., \& RodriguezCoello, A. (2004). Teaching teenagers with autism to seek assistance when lost. Journal of Applied Behavior Analysis, 37(1), 79-82.

Test, D. W., Aspel, N. P., \& Everson, J. M. (2006). Transition methods for youth with disabilities. Upper Saddle River: Pearson Prentice Hall. 
*Todd, T., \& Reid, G. (2006). Increasing physical activity in individuals with autism. Focus on Autism and Other Developmental Disabilities, 21(3), 167-176.

*Van Laarhoven, T., Kraus, E., Karmpan, K., Nizzi, R., \& Valentino, J. (2010). A comparison of picture and video prompts to teach daily living skills to individuals with autism. Focus on Autism and Other Developmental Disabilities, 25(4), 195-208. doi:10.1177/ 1088357610380412.

Volkmar, F. R., \& Wiesner, L. A. (2009). A practical guide to autism: What every parent, family member, and teacher needs to know. Hoboken: John Wiley \& Sons, Inc.

*Vuran, S. (2007). Empowering leisure skills in adults with autism: An experimental investigation through the most-to-least prompting procedure. International Journal of Special Education, 22(3), 174181.

*Waters, H. E., \& Boon, R. T. (2011). Teaching money computation skills to high school students with mild intellectual disabilities via the TouchMath $($ program: A multi-sensory approach. Education and Training in Autism and Developmental Disabilities, 46(4), 544-555.

Wehman, P., Smith, M. D., \& Schall, C. (Eds.). (2009). Autism and the transition to adulthood: Success beyond the classroom. Baltimore: Paul H. Brookes Publishing Co.

Wolery, M., \& Lane, K. L. (2010). Writing tasks: Literature reviews, research proposals, and final reports. In: D. L. Gast (Ed.) Single subject research methodology in behavioral sciences (pp. 57-90). New York: Routledge. 